\title{
Financial Gains and Moral Satisfaction as Key Factors for Greater Efficiency in the Field of Education
}

\author{
Vasiliki Brinia ${ }^{1}$, Stavroula Leimoniti ${ }^{2}$ and Alexandros Dimos ${ }^{1, *}$ \\ 1 Teacher Education Program, Athens University of Economics and Business, 10434 Athens, Greece; \\ vbrinia@aueb.gr \\ 2 Educational Sciences, Hellenic Open University, 26335 Patras, Greece; stauroulalei@gmail.com \\ * Correspondence: a.dimos@acg.edu
}

Citation: Brinia, V.; Leimoniti, S.;

Dimos, A. Financial Gains and Moral Satisfaction as Key Factors for Greater Efficiency in the Field of Education. Educ. Sci. 2021, 11, 236. https:// doi.org/10.3390/educsci11050236

Academic Editor: James Albright

Received: 18 March 2021

Accepted: 9 May 2021

Published: 14 May 2021

Publisher's Note: MDPI stays neutral with regard to jurisdictional claims in published maps and institutional affiliations.

Copyright: (c) 2021 by the authors. Licensee MDPI, Basel, Switzerland. This article is an open access article distributed under the terms and conditions of the Creative Commons Attribution (CC BY) license (https:// creativecommons.org/licenses/by/ $4.0 /)$.

\begin{abstract}
The present study examines teachers' perceptions regarding moral satisfaction, financial gain and professional motivation in order to examine the relationship between these factors and their work efficiency. The degree of agreement and disagreement in the perceptions of 270 Primary Education teachers, regarding the extent to which their effectiveness at work is affected by the existence of the above factors, is studied, and the study was conducted in 31 primary schools in Greece. The size of the sample and the way the results are extracted is a key innovation of the research, as for the first time, the above concepts are quantified through the answers of those involved in education. Their answers are examined by the method of quantitative research and the statistical program IBM-SPSS 24. It appears that moral rewards, the relationship with their manager and colleagues and their degree of self-esteem are elements that, if increased and positive, lead to higher productivity in their work. The recognition of the overall offer of the teachers by colleagues, the manager, society and the state have a positive effect on the effectiveness of their work, while its lack reduces their motivation to be efficient.
\end{abstract}

Keywords: primary education teachers; teachers' effectiveness; motivations; teachers' perceptions

\section{Introduction}

Motivation and productivity are two concepts of great interest for both researchers and professionals. Both concepts have been defined in different ways from various researchers, and it takes much effort for these definitions to be revised. By the term "motivation," we mean the way in which an individual or a team is inspired to behave in a desirable way in order to receive a positive reward or to satisfy specific human needs [1]. On the other side, the concept of productivity, which is one of the most modern ones, is regularly used in the management sector nowadays. It is interpreted as the optimal utilization of resources for the production of goods, and the rendering of services, so that they correspond to the predetermined goals [2].

In general, the motivation theories can be classified into either the content theories or in the process theories. The first deals with the motivation and concerns for identifying the needs of people and their related forces, as well as the goals they seek to meet those needs. The basic content theories include the hierarchy needs of Maslow [1], Herzberg's Two Factors theory [3] as well as McClelland's theory of motivation [4,5]. On the other hand, process theories give emphasis on the real process of motivation. These theories deal with the relationship between the dynamic variables which constitute motivation and on how behavior starts and is directed and maintained. Some good examples are models based on expectation, the theory of goals of the equality theory as well as the distribution theory [6]. Self-Determination Theory, which is a general paradigm for studying human motivation and personality, lays out a meta-theory for framing motivational research, a systematic theory that distinguishes intrinsic and extrinsic origins of motivation, and a definition of 
the functions of intrinsic and extrinsic motivation in cognitive and social progress, as well as in individual differences [7].

Victor Vroom developed the theory of expectations based on the belief that employees' efforts will lead to performance, and this performance will lead to rewards. Rewards can either be positive or negative. The more positive the reward is, the more possible is that the employee will be highly motivated. In contrast, the more negative the reward is, the less possible is that the employee will be called to work harder [8].

The concept of internal motivation is directly linked to the one of performance. The term "performance" is a synonym of behavior. It is something that people do for real, and it can be observed. Specific incentives are designs to have predetermined criteria and standards, as well as understandable policies for the determination and distribution of rewards. Although money is possibly the most used incentive, incentives include anything provided by an external factor, dependent on the fulfillment of specific behavior standards. Thus, promotions, grades, awards, health benefits, praise and recognition are all incentives.

In each organization, human power is considered as the greatest resource because all functions which are related to functions of an organization are related to the individuals related to them. In other words, the success of an organization relates to the performance and the commitment of the employees as well as with the way that an employee succeeds the organizational goals and the effort that puts, in order to become an effective member of the team. The incentives are the most significant elements which contribute to the motivation of individuals but, at the same time, the importance of non-financial incentives cannot be neglected [9]. According to Gale, non-financial incentives are considered more significant than the financial ones. The researcher points out that, whenever people are paid for a good job, they consider it part of the salary [10].

Since the appearance of the paid job, as a way of organizing the work, many centuries ago, business owners faced problems motivating their employees in order to be productive at work. The academic bibliography analyzes this problem by utilizing a basic Factor model. In these models, directors are able to create incentive programs so that agents act at the interest of directors. In this research, we examine the issue of incentives from the employee's perspective, in contrast to the previous philosophy [1,11].

\section{Literature Review}

Several studies have been designed in order to examine the concepts of teachers' motivation and incentives. The study of $[12,13]$ was designed to examine the factors affecting the teacher's level of motivation at secondary education. The conclusion that emerged was that teachers were not satisfied with the socioeconomic situation, the choice of their job, the behavior of students and the stress of the exams, whereas many of them considered that their wage is not satisfactory for the level of their abilities. Thus, it was proposed that teachers should educate, receive the proper respect and get paid according to their qualifications and abilities.

The study of Hildebrandt and Eom [14] examined the motivational factors of teachers who have achieved a national level of vocational training. Using bilateral, online research, multiple incentives concerning the professionalism of teachers were revealed, with teachers of different ages who are motivated by different incentives. The objectives were developed based on previous researches and separated in different categories: the economic profit, recognition and affirmation, personal satisfaction, career development, career promotion, enhanced leadership role and the opportunity to cooperate with other teachers as they become better.

The improved teaching incentives represented teachers' desires for career and educational development. The previous studies indicate that teaching usually urges teachers to engage in career training activities. For example, Peker underlined that the improvement of practice and the enhancement teacher's job are usually referred as incentives [15]. "The Center for the Future of Teaching and Learning" found that strengthening the teaching of everyone is directly related to obtaining a certification and, therefore, to the concept 
of professionalism [16]. Given that professionals constantly develop skills and knowledge [17], the ability as a psychological need [18] and the motivational factor are crucial. Financial incentives were used as an independent variable in this study, which enhances the popularity of the subject in current educational policy cycles. This research underlines the sustainability of economic profit as incentive for teachers.

In this context, Kelley and Kimball [19] found that money was initially a strong attraction tool in the process of professionalization, but later, this attraction declined as other incentives were strengthened. Certain countries and regions provide some teachers who get certified and specialize more and more with economic incentives, although this kind of practice changes in today's economic environment [15]. Given the relatively low wages of teachers compared with other sectors, motivation is an interesting and crucial factor for this study.

The synergistic opportunities appeared as other motivational factors. Peker (2004) mentioned that it was the most commonly mentioned incentive for certification from their participants, and Park et al. found that the teachers' interactions, as they work towards professionalization, made cooperation easier $[15,20]$. Past research on teaching environments and collaborative opportunities has shown that teachers often work individually [21], while more recent research has shown that teachers responded more positively when given the opportunity to work with others [19]. The independence of this factor indicates that cooperation is incentive for the certification and the professionalism that accompanies it. This factor is further supported by [22], who emphasized that teachers' cooperation was an integral part of their career development. Finally, the incentive of cooperation strengthens the psychological need for kinship among teachers.

Teachers' relationships are an important factor in their development. In many cases, these are directly related to the relationship between teachers and parents. Teachers appeared to see their relationships with parents favorably when they indicated high levels of psychological empowerment or were more likely to see their organizational culture as a group, developmental and hierarchical culture [23]. Finally, after adjusting for the ethnic profiles of teachers, psychological empowerment and organizational culture uniquely predicted teacher-parent relationships.

Affirmation is an interesting source of incentives for teachers in this research, although it did not constitute a single factor. Internal and external affirmation, as independent factors, came up from the data content of this research. Supporting this difference, Fernet differentiates these control positions, explaining that the particular adjustment is the behavior that people choose to execute because it is in accordance to their own values and goals, whereas the external adjustment occurs when behaviors adjust in order to obtain a reward or to avoid a restriction [24]. Internal affirmation is a basic incentive, because teachers do not necessarily receive external affirmation. In this context, teachers of California found "personal challenge" as one of the most important incentives for the certifications to occur, and Ozcan used "honorary rewards" in his model regarding teachers' motivation as he described the "social honor, status and recognition" [4,25].

This multifaceted concept of incentive for professionalism strengthens the previous research, whereas it decomposes specific major categories of incentives for teachers. This multidimensional structure of incentives seeks to encourage further discussions between teachers, researchers and others with regards to why teachers choose to pursue professionalization, especially if it is not mandatory [26]. Professionalization and growth are especially necessary when hiring, training and retaining teachers who are dedicated to equitable education in both developed and developing countries, which are historically, and currently, underserved and underserved much too often [27].

During the last two decades, many studies have tried to locate sources of both satisfaction and dissatisfaction for teachers of all educational levels [12]. According to the majority of these studies, the satisfaction of teachers relates to the levels of introspection i.e., with the incentives. The main factor that contributes to the teachers' work satisfaction is the interaction with children. Additional factors were the development of warm, 
personal relationships with the students, the spiritual challenge of thinking, autonomy and independence. On the contrary, many teachers faced job dissatisfaction, focusing mainly on work overload, poor pay and perceptions of how teachers are treated by society. In general, however, studies have found differences in teacher satisfaction with work, depending on certain individual and school characteristics [28]. Job dissatisfaction can lead to exhaustion, the increase in job stress, and, in this case, the burnout of a teacher may appear [29]. Four key categories have been categorized into factors influencing or affecting job satisfaction/dissatisfaction and motivation: human factors, actual work factors, organizational factors and social context factors. These factors were investigated and it came out that teachers can be satisfied when specific activities, regarding their daily activities, can be completed on time [30].

According to Zembylas and Papanastasiou, the satisfaction of teachers refers to the emotional relationship of teachers with their teaching role, and it is a function of the perceived relationship between what one wants from teaching and what he actually realizes is offered to a teacher [31,32]. Those who have the biggest desires or the highest ambitions are less pleased with their job if the environment does not satisfy their needs. In this context, Maeroff characterized teachers' "feeling of empowerment" as an important way "to make teachers more professional and improve their performance". The power that Maeroff mentioned, is "the power of someone to practice art with confidence and to contribute to the formation of the method with which the work should be done" [33].

The results of the above research indicated that the teachers in Cyprus chose the job of teaching staff for inherent reasons, as the majority of them stated that they always wanted to become teachers. Nevertheless, a more careful look at these data revealed that it was the level of wage, the working hours and the duration of vacation period which made teachers choose this career. The preliminary investigation of the results of this research confirms what it has been found in other studies in developed countries, that the motivation of teachers (native or exogenous) relates to the work satisfaction. The interpretation we can give from the Cypriot example is that the higher the teachers' exogenous motivation (wage, work conditions), the more satisfied they are with their job.

The total results of these two analyses show that it is more possible for teachers who had a more realistic opinion for their job, before they start their training, to be satisfied with their career. Moreover, people who always wanted to become teachers and never experienced any pressure from their family to follow this career, it is more possible to be satisfied with the role of the teacher.

The consensus among researchers is that extrinsic factors, such as remuneration, working conditions, teaching equipment and resources and job security, or intrinsic factors, such as self-growth, self-efficacy, motivation and autonomy, to name a few, may influence job satisfaction. Past research results provide insights into the effect of both intrinsic and extrinsic factors influencing the satisfaction of teachers [34,35]. Iwu supports that interpersonal relationships is the key factor that affects the commitment of teachers to work [36].

\section{Materials and Methods}

The purpose of this research is to study the opinions of teachers regarding work incentives and how this relates to the effectiveness on their work. We also examine moral and financial incentives, as well as ways of motivation. According to the purpose of the study, the following research questions are set.

- Which are the teachers' opinions regarding the satisfaction from economic incentives, moral satisfaction and the motivation in the workplace?

- How does the efficiency of teachers relate to the satisfaction from economic incentives?

- How does the efficiency of teachers in their workplace relate to their moral satisfaction?

- How does the efficiency of teachers in their workplace relate to satisfaction from economic incentives, moral satisfaction and motivation? 


\subsection{Method}

In this research, the quantitative method for analyzing data was preferred. A exploratory quantitative research was conducted, both descriptive and of correlation, using questionnaire of Likert operational press questions, so that we measure the teachers' level of agreement at the dimensions under research [37]. Moreover, another reason for selecting the quantitative research is because the according to the 2 nd, 3rd and 4th research question, the study of the relationship between the research's variables is necessary [38]. A big advantage of the quantitative studies is the fact that the findings can be generalized for the broader population, as long as the sample is representative for the population. Due to the large sample of this research, this method is the most appropriate in order to create representative results $[39,40]$.

\subsection{Sample and Demographics}

The population of the research includes all teachers of primary education. The sample consists of 270 teachers of primary education, 27-60 years old, with 11-20 years of prior working experience, who currently hold deputy positions in the public sector, with monthly wages of $600-1000 €$. The mean monthly wage of the participants was $918,60 €$. The mean of the working experience of the sample was 13.1 years of working experience. 112 of them were men and 158 were women.

Of the respondents, $158(58.5 \%)$ were women and $112(41.5 \%)$ men. Regarding the age of the sample, $132(49 \%)$ were between $31-40$ years old, 63 (23\%) up to 30 years old, $46(17 \%)$ 41-50 years old and 29 (11\%) 51-60 years old. The mean age of them was 36.7 years old. Regarding marital status, $56 \%$ were married and $44 \%$ were single. Regarding the level of education, $138(51 \%)$ stated higher education, $130(48 \%)$ postgraduate and $2(1 \%)$ doctoral. The detailed tables are placed in Appendix A section.

\subsection{Data Analysis}

The data analysis was conducted using the statistical software IBM SPSS 24, whereas the Microsoft office Excel was used for the graphs design. The operative variables and the quantitative ones of the research were presented with means and standard deviations, whereas the qualitative ones with frequencies and percentages. For testing the correlation of self-efficacy with the rest quantitative variables, the Pearson correlation coefficient was used, which gets values between -1 and 1 . The null hypothesis is that variables are linearly unrelated and the alternative one is that they are linearly correlated. The predictive variables of self-efficacy were determined by conducting multiple regression analysis. Selfefficacy was used as the dependent variable and the independent variables included moral satisfaction, satisfaction from economic incentives and motivation. The null hypothesis of the test is that the multiple linear model is not very strong, i.e., the explanatory variables are statistically insignificant, whereas the alternative is that they are statistically significant. In case of adjustment, the strength of the model is determined by the adjusted $R^{2}$ and values above 0.25 are considered satisfactory. The previously mentioned tests were conducted at $5 \%$ level of significance. The reliability of the data was calculated with the Cronbach Alpha coefficient, where values greater than 0.7 are considered satisfactory acceptable. All the factors under study had satisfactory reliability as the values of the coefficient were greater than or equal to 0.705 .

To cover deontological issues, a number of rules were observed. Before the research was conducted, the researcher was granted permission from the Institutional body. Additionally, permission for the distribution of the questionnaires was asked from the primary education's management. Finally, teachers, before filling in the questionnaires, were informed regarding the purpose of the research as well as for the fact that they participate voluntarily and anonymously and that their answers will be used for scientific purposes only. 


\subsection{The Questionnaire}

The research questionnaire consists of 51 questions and is divided into 5 sections. The 1st section refers to the demographic data and consists of 4 closed-ended questions and the 2nd to the data questions with 6 questions, of which 5 are closed-ended and 1 five-point Likert scale 1-5 (1-Not at all, 2-A little, 3-Moderate, 4-Enough, 5-Very), on the dependent research variable that is work efficiency. Section 3 includes 12 Likert 1-5 five-point type questions (1-Not at all, 2-A little, 3-Moderate, 4-Enough, 5-A lot), refers to satisfaction with financial earnings and is based on Spector's JSS questionnaire (1985). In the Section 3, the satisfaction from the salary (4 questions), the additional benefits (4 questions) and the promotion (4 questions) are studied. Section 4 deals with moral satisfaction, includes 20 five-point Likert 1-5 questions (1-Not at all, 2-A little, 3-Moderate, 4-Enough, 5-A lot) and is based on the JSS questionnaire of Spector (1985) and Rosenberg (1965). In the Section 4, the satisfaction from the rewards (4 questions), the colleagues (3 questions) and the bosses (3 questions) are studied. Self-esteem levels are also studied (10 questions). The Section 5 includes 9 five-point Likert 1-5 (1-Not at all, 2-A little, 3-Moderate, 4-Enough, 5-A lot) questions about professional motivation (9 questions) and was made according to her work. Duke (2017). The duration of the questionnaire was $10 \mathrm{~min}$. The questionnaires were completed in the employees' workplace.

\section{Results}

In order to measure the three key factors in terms of the respondents' satisfaction with their financial earnings (Salary, Additional Benefits and Promotion), the respondents stated their degree of agreement through a five-point scale $(1=$ Not at all, $2=$ A little, $3=$ Moderate, $4=$ Enough, 5 = Very much). Their answers were placed between "moderate" and "sufficient," in terms of whether they think they are paid fairly for the work they do (average $=3.42 \pm 0.86$ ). They also answered "mediocre" about how much they feel their work is valued when they think about their pay (average $=3.09 \pm 0.94$ ). Finally, they answered that they feel a little satisfied with the opportunities for salary increases (Average $=2.13 \pm 0.65$ ), as well as a little agree that salary increases are frequent (Average $=1.77 \pm 0.56$ ).

Table 1 lists the answers related to the additional benefits. The respondents answered "a little," regarding whether they are satisfied with the additional benefits in addition to the salary ( $A V G=2.27 \pm 0.73)$, the package of additional benefits as well as whether the additional benefits are as good as those offered by other organizations ( $\mathrm{Avg}=2.25 \pm 0.73$ ). They then stated that they slightly agree with the argument that there are no other additional benefits they should receive $(\mathrm{Avg}=1.71 \pm 0.71)$.

Table 1. Answers related to the additional benefits.

\begin{tabular}{ccc}
\hline Suggestions & Avg & St. Dev. \\
\hline $\begin{array}{c}\text { I am satisfied with the additional benefits in addition to the salary } \\
\text { The additional benefits, in addition to the salary we receive in the } \\
\text { context of work, are fair }\end{array}$ & 2.27 & 0.73 \\
$\begin{array}{c}\text { The additional benefits—in addition to the salary we receive from } \\
\text { work—are just as good as those offered by other organizations } \\
\text { There are no other additional benefits we should receive }\end{array}$ & 2.27 & 0.72 \\
\hline
\end{tabular}

Table 2 lists the questions related to promotion. Respondents answered that they slightly agree with the views that there are opportunities for promotion in their work $(\mathrm{AVG}=1.75 \pm 0.59)$, as well as that they are satisfied with the promotion opportunities provided to them $(\mathrm{AVG}=1.72 \pm 0.61)$. Their answers were placed between "a little" and "moderate," in terms of whether they agree that those who do a good job have a good chance of promotion (Average $=1.53 \pm 0.56$ ), and as to whether they agree that employees in this job are promoted as fast as employees in other jobs (AVG $=1.43 \pm 0.54)$. 
Table 2. Answers related to promotion.

\begin{tabular}{ccc}
\hline Suggestions & Avg & St. Dev. \\
\hline There are opportunities for promotion in my work & 1.75 & 0.59 \\
I am satisfied with the promotion opportunities provided to me & 1.72 & 0.61 \\
Those who do a good job have several chances of being promoted & 1.53 & 0.56 \\
Employees here are promoted as fast as in other jobs & 1.43 & 0.54 \\
\hline
\end{tabular}

Respondents' moral satisfaction was measured by three factors: Rewards, Colleagues, Manager and Self-Esteem. Respondents stated their degree of agreement on a scale of 1 to $5(1=$ Not at all, $2=$ A little, $3=$ Moderate, $4=$ Enough, $5=$ Very much).

Table 3 shows the results regarding their moral satisfaction in terms of their rewards. They answered that they moderately agree with the arguments, that they get the recognition they deserve when they do their job (Average $=3.32 \pm 0.77$ ), their work is valued (Average $=3.31 \pm 0.78$ ), and their efforts are rewarded as they should be (AVG $=2.70 \pm 0.78$ ). Finally, their answers were placed between the little and the mediocre, regarding whether they agree that there are rewards for those who work in the specific area (Average $=2.55 \pm 0.74$ ).

Table 3. Moral satisfaction in terms of their rewards.

\begin{tabular}{ccc}
\hline Suggestions & Avg & St. Dev. \\
\hline When I do my job well, I get the recognition I need & 3.32 & 0.77 \\
I think my work is appreciated & 3.31 & 0.78 \\
I believe that my efforts are being rewarded as they should be & 2.70 & 0.78 \\
There are rewards for those who work here & 2.55 & 0.74 \\
\hline
\end{tabular}

Table 4 lists the questions that relate to the moral satisfaction of the respondents in relation to their colleagues. Respondents stated that they quite like the people they work with (Average $=4.09 \pm 0.58$ ), and that they have a good time with them (Average $=4.08 \pm 0.60$ ). Finally, they stated that they moderately agree with the fact that there are few quarrels and disputes at work (AVG $=3.32 \pm 1.08)$.

Table 4. Moral satisfaction in relation to colleagues.

\begin{tabular}{ccc}
\hline Suggestions & Avg & St. Dev. \\
\hline I like the people I work with & 4.09 & 0.58 \\
I have a good time with my colleagues & 4.08 & 0.60 \\
There are few quarrels and disputes at work & 3.32 & 1.08 \\
\hline
\end{tabular}

Table 5 presents the questions, which relate to the moral satisfaction of the respondents by their manager. Respondents stated that they like their manager a lot (Average $=4.18 \pm 0.53$ ), he is quite fair with them (Average $=4.18,50.53$ ), as well as that he shows a lot of interest for how they feel (AVG $=4.03 \pm 0.63)$.

Table 5. Moral satisfaction and manager.

\begin{tabular}{ccc}
\hline Suggestions & Avg & St. Dev. \\
\hline I sympathize my boss & 4.18 & 0.53 \\
My boss is fair to me & 4.18 & 0.53 \\
My boss is interested in how I feel & 4.03 & 0.63 \\
\hline
\end{tabular}

Next, Table 6 presents the questions related to self-esteem. Respondents answered "enough" about whether they are satisfied with themselves at work (Average $=4.31 \pm 0.48$ ), have a positive attitude towards themselves (Average $=4.18 \pm 0.71$ ) and whether they are able to do things as well as others in their work $(\mathrm{AVG}=3.96 \pm 0.64)$. Their answers 
were placed between "moderate" and "sufficient," regarding whether they think they are worth at least as much as others in their work (average $=3.61 \pm 0.82$ ), as well as how much they feel they possess enough qualifications for their job (Average $=3.50 \pm 1.08$ ). They also stated that they agree a little with the positions that they do not have enough reasons to be proud of their work (Average $=2.46 \pm 0.70$ ), sometimes, they think that they are not good at all (Average $=1.98 \pm 0.71)$ and that they are not useful $(\mathrm{AVG}=1.88 . \pm 0.64$ ). They also agreed a little, with the suggestion that they would like to have more respect for themselves (AVG $=1.87 \pm 0.61$ ), as well as that several times they tend to believe that they have failed in their work (M. O. $=1.86 \pm 0.63)$.

Table 6. Answers related to self-esteem.

\begin{tabular}{ccc}
\hline Suggestions & Avg & St. Dev. \\
\hline In general, I am satisfied with myself in my work & 4.31 & 0.48 \\
I have a positive attitude towards myself & 4.18 & 0.71 \\
I am able to do things as well as others in my job & 3.96 & 0.64 \\
I think I deserve at least as much as others in my work & 3.61 & 0.82 \\
I feel that I have enough qualifications for my job & 3.50 & 1.08 \\
I do not have enough reasons to be proud of my job & 2.46 & 0.70 \\
Sometimes I think I'm not good at my job & 1.98 & 0.71 \\
Sometimes I feel that I am not useful in my work & 1.88 & 0.64 \\
I wish I had more respect for myself & 1.87 & 0.61 \\
Many times I tend to think I have failed in my job & 1.86 & 0.63 \\
\hline
\end{tabular}

The last concept examined refers to the ways of motivation, which are applied in the workplace. The questions were answered on a scale of 1 to $5(1=$ Not at all, $2=$ A little, $3=$ Moderate, 4 = Enough, 5 = Very much).

According to the results of Table 7 , the respondents answered that they quite agree that the good school climate is applied (AVG $=3.91 \pm 0.78)$. They also stated that initiatives (Average $=2.96 \pm 0.70)$ and rewards (Average $=2.67 \pm 0.81$ ) are moderately implemented . Then, their answers were placed between "little" and "moderate" (average $=2.52 \pm 0.77$ ), regarding whether they consider group work to be done as a way of motivating the employee.

Table 7. Motivations.

\begin{tabular}{ccc}
\hline Suggestions & Avg & St. Dev. \\
\hline Good school climate & 3.91 & 0.78 \\
Taking initiatives & 2.96 & 0.70 \\
Rewards & 2.67 & 0.81 \\
Teamwork & 2.52 & 0.77 \\
Education, skills development & 2.32 & 0.69 \\
Teacher evaluation & 1.91 & 0.79 \\
Salary increase & 1.90 & 0.58 \\
Possibility of promotion & 1.70 & 0.66 \\
Group travel & 1.07 & 0.38 \\
\hline
\end{tabular}

Table 8 presents the results of the reliability analysis for the factors of the third, fourth and fifth module of the questionnaire, i.e., the modules concerning satisfaction with financial rewards, moral satisfaction and motivation. It turns out that for "Salary" it is $\alpha=0.794$, for "Additional benefits" $\alpha=0.943$, for "Promotion" $\alpha=0.898$, for "Rewards" $\alpha=0.912$, for the factor "Colleagues" $\alpha=0.705$, for the factor "Boss" $\alpha=0.952$, for the "Self-Esteem" $\alpha=0.795$ and for the factor "Ways of motivation" $\alpha=0.744$. The general factors "Satisfaction with financial incentives" were defined with $\alpha=0.908$, and "Ethical satisfaction" with $\alpha=0.839$.

For the answer to the first research question. Table 9 presents the descriptive elements of the factors. The scale of the answers is from 1-5. 
Table 8. Reliability analysis of modules 3, 4, 5 .

\begin{tabular}{ccc}
\hline Factors Questions & Factors Questions & Cronbach Alpha \\
\hline Salary & $11-14$ & 0.794 \\
Additional facilities & $15-18$ & 0.943 \\
Promotion & $19-22$ & 0.898 \\
Rewards & $23-26$ & 0.912 \\
Colleagues & $27-29$ & 0.705 \\
Chief & $30-32$ & 0.952 \\
Self esteem & $(34,37,38,40,41)$ & 0.795 \\
Ways of motivation & $\mathrm{R}, 33,35,36,39,42$ & 0.744 \\
Satisfaction with financial incentives & $43-51$ & 0.908 \\
Moral satisfaction & $11-22$ & 0.839 \\
\hline
\end{tabular}

Table 9. Research question 1 descriptive elements.

\begin{tabular}{ccc}
\hline Factors & Avg & St. Dev. \\
\hline Chief & 4.13 & 0.54 \\
Self esteem & 3.95 & 0.42 \\
Colleagues & 3.83 & 0.62 \\
Rewards & 2.97 & 0.68 \\
Salary & 2.60 & 0.60 \\
Ways of motivation & 2.33 & 0.40 \\
Additional facilities & 2.13 & 0.67 \\
Promotion & 1.61 & 0.50 \\
\hline
\end{tabular}

It turns out that the teachers often agree in terms of their satisfaction with the supervisor (AVG $=4.13 \pm 0.54)$, they feel enough self-esteem (AVG $=3.95 \pm 0.42)$ and are quite satisfied with colleagues ( $\mathrm{AVG}=3.83 \pm 0.62$ ). They are moderately satisfied with the rewards (Average $=2.97 \pm 0.68$ ), while a little to moderate with the salary (Average $=2.60 \pm 0.60$ ). Finally, the respondents consider that the ways of motivation are applied a little (Average $=2.33 \pm 0.40)$, as they agree a little in terms of their satisfaction with the additional benefits (Average $=2.13 \pm 0,67)$ and promotion $(\mathrm{AVG}=1.61 \pm 0.50)$.

To answer the second research question, Table 10 presents the results of Pearson correlations of financial motivation satisfaction factors with work efficiency. It turns out that "Productivity at work" shows a statistically significant positive correlation with:

- The "Salary" factor $(r=0.245, p<0.01)$ an

- The "Additional benefits" $(r=0.204, p<0.05)$.

Table 10. Financial motivation satisfaction factors with work efficiency.

\begin{tabular}{ccc}
\hline Pearson Correlations & Work Efficiency & Pearson Correlations \\
\hline Salary & $0.245^{* *}$ & Salary \\
Additional facilities & $0.204^{*}$ & Additional facilities \\
Promotion & 0.150 & Promotion \\
\hline${ }^{*}$ Statistically significant correlation at $1 \%{ }^{*}$ Statistically significant correlation at $5 \%$.
\end{tabular}

Table 11 presents the results of the coefficients of the multiple regression model with the dependent variable "Efficiency at work" and the independent satisfaction factors from financial incentives. It appears that the coefficient of the constant $(t=14.924, p<0.001)$ and the independent variable "Salary" $(B E T A=0.189, t=1.990, p=0.048)$ was considered statistically significant. The polylinearity was avoided in each case (Tolerance $>0,1$ and VIF < 10). The multiple linear model was determined by the following equation:

Productivity at work $=3.446+0.192 \times$ Salary $+0.083 \times$ Additional benefits $+0.024 \times$ Promotion 
Table 11. Efficiency at work.

\begin{tabular}{ccccccc}
\hline Independent Variables & $\mathbf{B}$ & $\boldsymbol{B E T A}$ & $\boldsymbol{t}$ & $\boldsymbol{p}$ & Tolerance & VIF \\
\hline Fixed term & 3.446 & & 14.924 & $<0.001$ & & \\
Salary & 0.192 & 0.189 & 1.990 & 0.048 & 0.708 & 1.412 \\
Additional facilities & 0.083 & 0.091 & 0.816 & 0.416 & 0.519 & 1.928 \\
Promotion & 0.024 & 0.020 & 0.192 & 0.848 & 0.612 & 1.635 \\
\hline
\end{tabular}

To answer the third research question, Table 12 presents the results of Pearson correlations of ethical satisfaction factors with work efficiency. It turns out that "Productivity at work" shows a statistically significant positive correlation with:

- $\quad$ The "Rewards" ( $r=0.169, p<0.05)$,

- The factor "Colleagues" $(r=0.282, p<0.01)$,

- The "Manager" factor $(r=0.469, p<0.01)$ and

- The "Self-Esteem" $(r=0.209, p<0.05)$.

Table 12. Productivity at work.

\begin{tabular}{cc}
\hline Pearson Correlations & Work Efficiency \\
\hline Rewards & $0.169^{*}$ \\
Colleagues & $0.282^{* *}$ \\
Manager & $0.469^{* *}$ \\
Self esteem & $0.209^{*}$ \\
\hline$* *$ Statistically significant correlation at $1 \% *^{*}$ Statistically significant correlation at $5 \%$
\end{tabular}

** Statistically significant correlation at $1 \%$. ${ }^{*}$ Statistically significant correlation at $5 \%$.

Table 13 presents the results of the coefficients of the multiple regression model with the dependent variable "Efficiency at work" and the independent factors of moral satisfaction. It turns out that the coefficient of the constant $(t=2.924, p=0.004)$ and the independent variables "Colleagues" (BETA $=0.157, t=2.045, p=0.043)$ and "Manager" $(B E T A=0.413, t=5.015)$ were considered statistically significant $(p<0.001)$. Multilinearity was avoided in each case (Tolerance $>0.1$ and $V I F<10$ ). The multiple linear model was determined by the following equation:

Productivity at work $=1.441-0.011 \times$ Rewards $+0.154 \times$ Colleagues $+0.469 \times$ Boss $+0.057 \times$ Self-esteem

Table 13. Moral Satisfaction and Productivity at work.

\begin{tabular}{ccccccc}
\hline Independent Variables & $\mathbf{B}$ & BETA & $\boldsymbol{T}$ & $\boldsymbol{p}$ & Tolerance & VIF \\
\hline Fixed term & 1.441 & & 2.924 & 0.004 & & \\
Rewards & -0.011 & -0.013 & -0.164 & 0.870 & 0.864 & 1.157 \\
Colleagues & 0.154 & 0.157 & 2.045 & 0.043 & 0.887 & 1.127 \\
Boss & 0.469 & 0.413 & 5.015 & $<0.001$ & 0.768 & 1.302 \\
Self esteem & 0.057 & 0.039 & 0.505 & 0.615 & 0.867 & 1.153 \\
\hline
\end{tabular}

To answer the fourth research question, Table 14 presents the results of Pearson correlations of general factors of satisfaction with financial motivation, moral satisfaction and motivation with efficiency at work. It turns out that "Productivity at work" shows a statistically significant positive correlation with:

- The factor "Ways of motivation" ( $r=0.230, p<0.01)$,

- "Satisfaction with financial incentives" $(r=0.245, p<0.01)$ and

- The "Ethical Satisfaction" $(r=0.371, p<0.01)$.

Table 15 presents the results of the coefficients of the multiple regression model with the dependent variable "Efficiency at work" and the independent general factors of satisfaction with financial motivation, moral satisfaction and motivation. It appears that 
the coefficient of the constant $(t=3.133, p=0.002)$ and the independent variable "Ethical satisfaction" (BETA $=0.387, t=3.821, p<0.001)$ were considered statistically significant. Multilinearity was avoided in each case (Tolerance $>0.1$ and VIF $<10$ ). The multiple linear model was determined by the following equation:

Productivity at work $=1.589-0.170 \times$ Motivation methods $+0.211 \times$ Satisfaction with financial incentives + $0.670 \times$ Ethical satisfaction

Table 14. Satisfaction with financial motivation, moral satisfaction and motivation with efficiency at work.

\begin{tabular}{cc}
\hline Pearson Correlations & Productivity at Work \\
\hline Ways of motivation & $0.230^{* *}$ \\
Satisfaction with financial incentives & $0.245^{* *}$ \\
Ethical satisfaction & $0.371^{* *}$ \\
\hline ** Statistically significant correlation at $1 \%$.
\end{tabular}

Table 15. Ethical satisfaction and Productivity at work.

\begin{tabular}{ccccccc}
\hline Indipendent Variables & $\mathbf{B}$ & $\mathbf{B E T A}$ & $\boldsymbol{T}$ & $\boldsymbol{p}$ & Tolerance & VIF \\
\hline Fixed term & 1.589 & & 3.133 & 0.002 & & \\
Motivation methods & -0.170 & -0.111 & -1.010 & 0.314 & 0.475 & 2.106 \\
Satisfaction with & 0.211 & 0.168 & 1.914 & 0.058 & 0.746 & 1.341 \\
financial incentives & 0.670 & 0.387 & 3.821 & $<0.001$ & 0.561 & 1.781 \\
Ethical satisfaction & & & & &
\end{tabular}

Table 16 presents the results of the coefficients of the multiple regression model with the dependent variable "Efficiency at work" and the independent factors-subsections of satisfaction with financial incentives, moral satisfaction and motivation. It appears that the coefficient of the constant $(t=2.604, p=0.010)$ and the independent variable "Manager" $(B E T A=0.416, t=4.904, p<0.001)$ were considered statistically significant. Multilinearity was avoided in each case (Tolerance $>0.1$ and VIF $<10$ ). The multiple linear model was determined by the following equation:

Productivity at work $=1.316+0.080 \times$ Salary $+0.071 \times$ Additional benefits $+0.027 \times$ Promotion $-0.024 \times$ Rewards $+0.113 \times$ Colleagues $+0.472 \times$ Boss $+0.099 \times$ Self-esteem $-0.111 \times$ Motivation methods

Table 16. Productivity at work and benefits.

\begin{tabular}{ccccccc}
\hline Indipendent Variables & $\mathbf{B}$ & $\boldsymbol{B E T A}$ & $\boldsymbol{T}$ & $\boldsymbol{p}$ & Tolerance & VIF \\
\hline Fixed term & 1.316 & & 2.604 & 0.010 & & \\
Salary & 0.080 & 0.079 & 0.803 & 0.423 & 0.542 & 1.847 \\
Additional facilities & 0.071 & 0.078 & 0.724 & 0.470 & 0.454 & 2.200 \\
Promotion & 0.027 & 0.022 & 0.222 & 0.824 & 0.540 & 1.853 \\
Rewards & -0.024 & -0.027 & -0.243 & 0.809 & 0.425 & 2.350 \\
Colleagues & 0.113 & 0.115 & 1.251 & 0.213 & 0.628 & 1.593 \\
Boss & 0.472 & 0.416 & 4.904 & $<0.001$ & 0.732 & 1.366 \\
Self esteem & 0.099 & 0.068 & 0.842 & 0.401 & 0.807 & 1.240 \\
Motivation methods & -0.111 & -0.073 & -0.584 & 0.560 & 0.338 & 2.960 \\
\hline
\end{tabular}

\section{Discussion}

In the first research question, teachers' views on satisfaction with financial incentives, moral satisfaction and motivation in the workplace were studied. Regarding moral satisfaction, satisfaction with rewards, the manager and colleagues, as well as the degree of self-esteem were studied. The views on the application of ways of motivation in the workplace were studied. Regarding financial incentives, salary satisfaction, additional benefits and promotion were studied. After all, as mentioned by [41], some incentives are 
projects that have predetermined criteria and standards, as well as understandable policies for determining and allocating rewards. Moreover, the results of the present study agree with the perspective of [32], who supports that teacher satisfaction refers to the relational connection that teachers have with their teaching roles, and it is a result of the assumed relationship between what a teacher expects from teaching and what he actually gets.

Initially, there was a high degree of agreement with the manager. Specifically, the respondents stated that they like their boss a lot, he is quite fair with them and shows a lot of interest in how they feel.

The research also concluded that teachers feel quite high self-esteem, as they answered that they are quite satisfied with themselves at work, have a positive attitude towards themselves and believe that they are quite capable of doing things as well as others in their work and that they are highly qualified. In addition, they disagreed that they did not have good reasons to be proud of their work, that sometimes they thought they were not good at all, nor useful. They also disagreed that they would like to have more respect for themselves, but also that they often tend to believe that they have failed in their work.

Quite a high agreement was observed among the teachers in terms of satisfaction from colleagues. To be precise, the respondents stated that they quite like the people they work with and have a good time with them. Satisfaction with the rewards was mediocre. The participants probably disagreed that there are rewards in the organization.

On the other hand, the participants showed moderate to low salary satisfaction. In particular, they stated that they feel a little dissatisfied with the opportunities for salary increases and that salary increases are rare. On the plus side, is that they believe that their pay is fair enough for what they do.

There seemed to be little satisfaction from the additional benefits and, especially, from those beyond the salary, because the participants did not consider the package of additional benefits, in addition to the salary received, to be very fair. There was also little agreement on whether the additional benefits are as good as those offered by other organizations. Finally, there was disagreement with the position that there are no other additional benefits that teachers should receive.

Even less satisfaction was found on the part of the respondents from their possible promotion. To be precise, they themselves seemed to agree to a very small degree that there are opportunities for promotion in their work and seemed to be a little satisfied with the promotion opportunities provided to them. In addition, they did not agree at all that those who do a good job have a good chance of being promoted and employees in this job are promoted as fast as in other jobs. In general, the above findings should be related to Greene's position that motivation is provided in order for individuals to make more efforts for desirable behaviors when they are promised motivation [41].

Then, according to the answers of the teachers, it was observed that they consider that the ways of motivation are applied a little. The only motivation that stood out and was reported to be applied is the good school climate. In the second research question, the way in which the effectiveness of teachers in their work is related to their satisfaction with financial incentives was studied. It was therefore concluded that the increased satisfaction with the salary and the additional benefits contributes to the increase in this efficiency. However, the most important factor that leads to greater effectiveness of participants is the high satisfaction with the salary, which is consistent with the finding of Pinder that money is probably the most widely used incentive [25].

In the third research question, the aforementioned effectiveness was studied in relation to the moral satisfaction of the participants. It has been observed that increased satisfaction with rewards, colleagues and the supervisor, as well as high self-esteem of teachers, lead to greater efficiency in their work. However, it is emphasized that the high degree of satisfaction from colleagues and the supervisor are the most important issues that create high work efficiency.

In the last research question, the correlation between efficiency at work and satisfaction with financial motivation, moral satisfaction and motivation was investigated again. 
In general, financial incentives are associated with higher performance, as [42] point out, depending on the type of performance and incentives.

Initially, in a general study, it was found that more application of motivation in the workplace, increased moral satisfaction and the corresponding financial incentives create higher work efficiency in teachers. However, high moral satisfaction is the factor with the greatest significance that leads to great efficiency. More specifically, studying the question, it was concluded that the great satisfaction of the respondents by the boss is the most important parameter of all that contributes to their great efficiency in matters of work, and as Sansone and Harackiewicz point out, intrinsic motivation is an important determinant performance [43]. On the other hand, as Vroom argues, exogenous motivation is motivation only to the extent that a person believes that achieving motivation is crucial to other worthwhile things [8].

The results are generalizable to young Primary school teachers up to the age of 40, who work in the public sector and have at least 10 years of professional experience. An additional possible limitation is the measurement of self-efficacy at work, which was expressed in the opinion of the employees, from the assessment they receive from the manager. This may involve a slight bias, as self-efficacy levels are likely to be higher than actual. Future research in Primary education is proposed with a more representative sample, in terms of age, and by measuring self-efficacy according to the evaluation of the administration.

According to the literature review the cooperation with children was discovered to be the most important aspect that contributes to teachers' job satisfaction [18]. The results of the research reinforce this view, as they showed that the teachers who participated in it tend to characterize their profession as a function with a strong element of social contribution.

The recognition of the overall contribution that the teachers included in the sample receive from colleagues, the manager, society and the state has a positive effect on the effectiveness of their work, while the lack of it reduces their motivation to provide efficient work. The fact that the teachers who participated in the research showed a high degree of agreement in terms of satisfaction with their relationship, with the principal and other colleagues and the existence of a good atmosphere within the school community, while at the same time feeling quite high self-esteem in terms of performance in their work, with the common acceptance of a moderate to low salary satisfaction and a small satisfaction with their possible promotion, shows that they receive much more moral rewards than financial ones, confirming the view that the teaching profession it is not a profession in itself but a function for society.

\section{Limitations of The Present Study and Suggestions for Future Research}

Given that the present study was conducted in the midst of a pandemic, data collection was gradual due to the large sample. Its limitations mainly concern the sample that was examined, as it consists of Primary education teachers. It would be quite interesting to consider, in future research, the point of view of Secondary education teachers by studying additional parameters such as this interaction with their students. Clearly, such a thing, on a smaller scale, could be done through qualitative research and conducting interviews. In addition, the qualitative approach allows the collection of useful and valuable empirical material. Moreover, the qualitative approach helps us collect useful empirical material, such as mismatches and variabilities, in a person's speech or behavior. These elements are not usually taken into account by the quantitative approach but can be used as data in order to interpret difficulties and internal tensions [44].

\section{Conclusions}

In the present study, the perceptions of 270 Primary Education teachers about the extent to which their effectiveness at work is affected by the existence or absence of a number of factors, such as moral satisfaction, financial gain and ways of motivation were studied. The role of teachers in a society is multifactorial, while it is influenced and shaped 
by both internal and external factors. The results of the research showed that the teachers who participated in it tend to characterize their profession as a function with a strong element of social contribution. In addition, it turns out that the most important factor that directly affects their work efficiency is moral satisfaction along with the element of providing higher financial rewards. In a more general context, it appears that moral rewards, the relationship with the manager and colleagues and their degree of self-esteem are elements that, if they are both increased and positive, lead to the development of higher efficiency in the work they produce. Finally, the results of the research showed that the effectiveness of teachers in their work is strongly related to their satisfaction with financial incentives, with salary satisfaction contributing to the increase in this efficiency. Nevertheless, the high degree of satisfaction from colleagues and the manager are the most important issues that create high efficiency at work.

Author Contributions: Formal analysis, V.B.; Resources, A.D.; Supervision, V.B.; Validation, A.D.; Writing-original draft, V.B. and S.L.; Writing—review \& editing, A.D. All authors have read and agreed to the published version of the manuscript.

Funding: This research received no external funding.

Conflicts of Interest: The authors declare no conflict of interest.

\section{Appendix A}

Tables A1 and A2 shows detailed data regarding the sample of the study.

Table A1. Descriptive Statistics I.

\begin{tabular}{cccc}
\hline Type & Category & N & F \\
\hline \multirow{2}{*}{ Gender } & Man & 112 & 41 \\
& Wooman & 158 & 59 \\
\hline \multirow{3}{*}{ Age } & $>30$ & 63 & 23 \\
& $31-40$ & 131 & 49 \\
& $41-50$ & 47 & 17 \\
Marital status & $51-60$ & 29 & 11 \\
& Married & 151 & 56 \\
& Not Married & 119 & 44 \\
\hline \multirow{3}{*}{ Level of Education } & Bachelor Degree & 139 & 51 \\
& Masters Degree & 128 & 48 \\
& PhD & 3 & 1 \\
\hline
\end{tabular}

Table A2. Descriptive Statistics II.

\begin{tabular}{ccc}
\hline Type & Category & $\mathbf{f} \%$ \\
\hline \multirow{3}{*}{ Years of service } & $>5$ & 12.7 \\
& $6-10$ & 13.3 \\
& $11-15$ & 46.7 \\
Monthly earnings (in $€)$ & $16-20$ & 16.7 \\
& $<20$ & 10.7 \\
\hline \multirow{2}{*}{ Work area } & $>600$ & 0.7 \\
& $600-1000$ & 69.3 \\
Working condition & $1000-1400$ & 30.0 \\
\hline \multirow{2}{*}{. } & Private sector & 9.3 \\
& Public sector & 90.7 \\
\hline
\end{tabular}




\section{References}

1. Maslow, A.H. A Dynamic Theory of Human Motivation. In Understanding Human Motivation; Stacey, C.L., DeMartino, M., Eds.; Howard Allen Publishers: Cleveland, OH, USA, 1958; pp. 26-47. [CrossRef]

2. Bawa, M.A. Employee Motivation and Productivity: A Review of Literature and Implications for Management Practice. Int. J. Econ. Commer. Manag. 2017, 12, 663-673.

3. Herzberg, F.B. Work and the Nature of Man; The World Publishing Company: Cleveland, OH, USA, 1966.

4. McClelland, D.C. Toward a theory of motive acquisition. Am. Psychol. 1965, 20, 321. [CrossRef]

5. Maslow, A.H. Preface to motivation theory. Psychosom. Med. 1943. [CrossRef]

6. Uzonna, U.R. Impact of Motivation on Employees Performance: A Case Study of CreditWest Bank Cyprus. J. Econ. Int. Finance 2013, 5, 199-211. [CrossRef]

7. Deci, E.L.; Ryan, R.M. Self-Determination Research: Reflections and Future Directions; University of Rochester Press: Rochester, NY, USA, 2002.

8. Vroom, V.H. Work and Motivation; Wiley: Oxford, UK, 1964.

9. Gerhart, B.; Rynes, L.S.; Minette, A.K. The Importance of Pay in Employee Motivation: Discrepancies between What People Say and What They Do. Hum. Resour. Manag. 2004, 43, 381-394.

10. Gale, S.F. Small Rewards Can Push Productivity. Workforce. Workforce 2002, 81, 86-90.

11. Ganta, V.C. Motivation in the workplace to improve the employee performance. Int. J. Eng. Technol. Manag. Appl. Sci. 2014, 2, 221-230.

12. Farber, B.A. Crisis in Education: Stress and Burnout in the American Teacher; Jossey-Bass: San Francisco, CA, USA, $1991 ;$ p. 81.

13. Alam, M.T.; Farid, S. Factors affecting teachers motivation. Int. J. Bus. Soc. Sci. 2011, 2, 298-304.

14. Hildebrandt, S.A.; Eom, M. Teacher professionalization: Motivational factors and the influence of age. Teach. Teach. Educ. 2011, 27, 416-423. [CrossRef]

15. Peker, D. Teacher Motivation to Participate in National Board Certification; CSU e-Press: San Diego, CA, USA, 2004.

16. National Association of Secondary of Secondary School Principals. Principals and After-School Programs: A Survey of preK-8 Principals; Belden Russonello and Stewart, Research and Communications: Alexandria, VA, USA, 2001.

17. Glasser, W. The Quality School Teacher; Special Markets Department, Harper-Collins Publishers, Inc.: New York, NY, USA, 1993.

18. Dzubay, D. Understanding Motivation \& Supporting Teacher Renewal; Quality Teaching and Learning Series; ERIC: Portland, OR, USA, 2001; Volume 1.

19. Kelley, C.; Kimball, S.M. Financial incentives for National Board certification. Educ. Policy 2001, 15, 547-574. [CrossRef]

20. Park, S.; Oliver, J.S.; Johnson, T.S.; Graham, P.; Oppong, N.K. Colleagues' roles in the professional development of teachers: Results from a research study of National Board certification. Teach. Teach. Educ. 2007, 23, 368-389. [CrossRef]

21. Lortie, D. 1975 School Teacher: A Sociological Study; University of Chicago Press: Chicago, IL, USA, 1975.

22. Grant, A.M. Does intrinsic motivation fuel the prosocial fire? Motivational synergy in predicting persistence, performance, and productivity. J. Appl. Psychol. 2008, 93, 48-58. [CrossRef] [PubMed]

23. Chung, K.S.; Kim, M. The impact of psychological empowerment and organizational culture on the early childhood teacher-parent partnerships in South Korea. Child. Sch. 2018, 40, 145-154. [CrossRef]

24. Fernet, C.; Senécal, C.; Guay, F.; Marsh, H.; Dowson, M. The work tasks motivation scale for teachers (WTMST). J. Career Assess. 2008, 16, 256-279. [CrossRef]

25. Pinder, W.C.C. Work Motivation in Organizational Behaviour, 2nd ed.; Psychology Press: New York, NY, USA, 2011.

26. Bergmark, U. Teachers' professional learning when building a research-based education: Context-specific, collaborative and teacher-driven professional development. Prof. Dev. Educ. 2020, 1-15. [CrossRef]

27. Fisher-Ari, T.R.; Martin, A.; Cox, V.; Granville, H.G.; Forstner, L. Community-Oriented PDS Programs: Professionalizing Teachers, Supporting Learners, and Reshaping Discourses around Teaching. Sch.-Univ. Partnersh. 2019, 12, 17-30.

28. Spear, M.; Gould, K.; Lee, B. Who Would Be a Teacher? A Review of Factors Motivating and Demotivating Prospective and Practising Teachers; NFER: Slough, UK, 2000.

29. Lee, J. Effects of a working environment causing exhaustion on job stress of childcare teachers. GSJ 2020, 8, 1709-1718.

30. Sahito, Z.; Vaisanen, P. Factors Affecting Job Satisfaction of Teacher Educators: Empirical Evidence from the Universities of Sindh Province of Pakistan. J. Teacher Educ. Educ. 2017, 6, 5-30.

31. Lawler, E.E., III. Motivation in Work Organizations; ERIC: Portland, OR, USA, 1973.

32. Zembylas, M.; Papanastasiou, E. Job satisfaction among school teachers in Cyprus. J. Educ. Admin. 2004. [CrossRef]

33. Maeroff, G.I. The Empowerment of Teachers. Overcoming the Crisis of Confidence; Teachers College Press: New York, NY, USA, 1988.

34. Baroudi, S.; Tamim, R.; Hojeij, Z. A Quantitative Investigation of Intrinsic and Extrinsic Factors Influencing Teachers' Job Satisfaction IN Lebanon. Leadersh. Policy Sch. 2020, 1-20. [CrossRef]

35. Wernimont, P.F. Intrinsic and extrinsic factors in job satisfaction. J. Appl. Psychol. 1966, 50, 41. [CrossRef] [PubMed]

36. Iwu, C.G.; Ezeuduji, I.O.; Iwu, I.C.; Ikebuaku, K.; Tengeh, R.K. Achieving quality education by understanding teacher job satisfaction determinants. Soc. Sci. 2018, 7, 25. [CrossRef]

37. Cresswell, T. Place: A Short Introduction; John Wiley \& Sons: Hoboken, NJ, USA, 2013.

38. Hayes, J.R. The Complete Problem Solver; Routledge: New Jersey, NJ, USA, 2013.

39. Cohen, L.; Manion, L.; Morrison, K. Observation. Res. Methods Educ. 2007, 6, 396-412. 
40. Queirós, A.; Faria, D.; Almeida, F. Strengths and limitations of qualitative and quantitative research methods. Eur. J. Educ. Stud. 2017. [CrossRef]

41. Greene, R.J. Rewarding Performance: Guiding Principles, Custom Strategies; Routledge: New York, NY, USA, 2011.

42. Condly, S.J.; Clark, R.E.; Stolovitch, H.D. The effects of incentives on workplace performance: A meta-analytic review of research studies. Perform. Improv. Q. 2003, 16, 46-63. [CrossRef]

43. Sansone, C.; Harackiewicz, J.M. (Eds.) Intrinsic and Extrinsic Motivation: The Search for Optimal Motivation and Performance; Academic Press: San Diego, CA, USA, 2000.

44. Isari, F.; Pourkos, M. Qualitative Research Methodology. Applications in Psychology and Education; SEAV: Athens, Greece, 2015. 